\title{
Methodology and demographics of a single blinded, randomized controlled trial of chiropractic compared to physical therapy for balance impairments in community dwelling geriatric patients with or without low back pain
}

\author{
Dennis E Enix ${ }^{1 * \dagger}$, Kasey L Sudkamp ${ }^{1 \dagger}$, Theodore K Malmstrom ${ }^{2+}$ and Joseph H Flaherty ${ }^{3+}$
}

\begin{abstract}
Background: Postural control problems effect between 28\% and 35\% of individuals over the age 65 and increases with age. Musculoskeletal pain in the elderly impacts 20\% to 49\% of people between the ages of 65 and 75 , is a leading falls risk factor, and a robust predictor of morbidity. Polypharmacy in the management of chronic pain is common in the geriatric population. Conservative treatment options for balance and back pain are underrepresented in scientific literature.

Methods: The methods and demographics for a prospective, randomized controlled single blinded clinical trial are described. This study evaluated the use of either chiropractic care or physical therapy as a treatment for patients with balance problems and with low back pain (68.5\%) or without low back pain (31.5\%) in the geriatric population. One hundred and sixty eight consecutively enrolled community dwelling adults between 60 and 85 years old (72.8 +/- 6.8) were randomly assigned to 6 weeks of either chiropractic care or physical therapy (12 - 18 visits). Testing occurred prior to randomization, after 6 weeks of treatment, and again 6 weeks later. Functional and self-report outcome measures for balance included the Berg Balance Scale, Performance Oriented Mobility Assessment, Timed Up and Go Test, and NeuroCom balance tests. Pain was assessed with the Visual Analog Scale, 21-Point Box Scale, and pressure algometry. Quality of life healthcare questionnaires included the Oswestry, the SF-36, and the Falls Efficacy Scale for confidence in performing everyday activities. Data analysis for this intent-to-treat design was a mixed-model analysis of variance (ANOVA) $(p<0.05)$ and Bonferroni correction $(p<0.017$ and $p<0.025)$. This study was set in a university biomedical and healthcare research facility and university ethics committee approval was obtained and written informed consent was given by all study participants.
\end{abstract}

Conclusion: The methodology of this multimodal treatment protocol for balance disorders and low back pain in the geriatric population and patient demographics are described in this paper. Additional research in this area is needed for this growing at risk population.

Trial registration: NCT02031562.

Keywords: Balance, Falls, Geriatric, Back pain, Chiropractic, Physical therapy

\footnotetext{
*Correspondence: dennis.enix@logan.edu

'Equal contributors

${ }^{1}$ Research Division, Logan University, 1851 Schoettler Rd, Chesterfield, MO

60317, USA

Full list of author information is available at the end of the article
}

\section{Biomed Central}

(c) 2014 Enix et al.; licensee BioMed Central Ltd. This is an Open Access article distributed under the terms of the Creative Commons Attribution License (http://creativecommons.org/licenses/by/2.0), which permits unrestricted use, distribution, and reproduction in any medium, provided the original work is properly credited. The Creative Commons Public Domain Dedication waiver (http://creativecommons.org/publicdomain/zero/1.0/) applies to the data made available in this article, unless otherwise stated. 


\section{Background}

Low back pain (LBP) is an important clinical, socioeconomic, and public health problem and is the most frequently reported musculoskeletal condition, effecting between $20 \%-49 \%$ of adults over the age of 65 [1-5]. In the 2002 National Center for Health Statistics National Health Interview Survey of 31,044 adults, 49 percent of individuals over the age of 65 reported back pain within the past year, while 26.4 percent reported having at least one day of back pain within the past three months [4], with estimates of a lifetime prevalence affecting over 85 percent of individuals [3-5]. It continues to be one of the top contributing factors in number of years lived with disability, with falls listed as one of the top causes of years of life lost due to premature mortality [5,6]. The two are linked as LBP is related to a 2 -fold increase in risk of falling and an increased difficulty performing daily living activities [7]. Repeated bouts of back pain impact the daily functioning of the elderly patient and the presence of LBP is strongly linked to an increase in fall risk $[2,7,8]$. Within the population of communitydwelling older adults, between $30 \%$ and $40 \%$ fall at least once per year and fall related injuries are a leading cause of hospitalization in the United States [6,9].

The pathology of LBP related balance problems in the elderly is multifactorial including inhibition of core stabilizing muscles, multifidus muscle atrophy, altered muscle activation patterns, loss of proprioception, and an inability to control normal postural sway [10-13]. Recurring falls has been reported in older adults who have increased postural sway and narrow stances [14]. Individuals with LBP have modified postural strategies when they experience situations that tax their dynamic balance and limits of stability [15]. They tend to exhibit altered response patterns characterized by reduced peak trunk torque, increased co-activation of proximal musculature and enhanced distal muscle activation [16]. The ability to maintain standing balance depends on the functions of the visual, vestibular, and somatosensory systems but also requires proper sensory-motor integration [17].

There is evidence that the most effective treatment strategy for LBP and balance problems in older adults consists of a multimodal approach of exercise [18], manual therapy [19], and behavioral modification programs [19]. A review of 40 randomized controlled trials combining different interventions showed a significant reduction in the risk and rate of falls when multiple therapies were utilized [19]. Exercise programs alone have shown to reduce fall rates in older people by $17 \%$ [20]. Spinal manipulation as a method of restoring normal motion of the lumbar spine and pelvis has been investigated in several studies [21-23]. Normal sagittal spinal alignment has been shown to play an important role in the reduction of fall risk [24]. Hawk et al. published feasibility clinical trials looking at the effects of chiropractic care on balance, dizziness and chronic pain in the elderly $[25,26]$. There is a need for further investigations on the effects of chiropractic on pain and balance. The methods and demographics for a prospective, randomized controlled single blinded clinical trial are described. This randomized controlled clinical trial compared chiropractic care to physical therapy as a treatment for geriatric patients with balance problems with or without low back pain.

\section{Methods}

This prospective clinical trial study consecutively enrolled and randomly assigned participants between the ages of 60 to 85 years into either a chiropractic treatment group or a physical therapy treatment group. A computer program was used to randomize participants to receive either 6 weeks of treatment (12-18 visits) in either the chiropractic care group or physical therapy group. All participants had self-reported balance problems with or without low back pain. This study was a collaboration with the Saint Louis University (SLU) Division of Geriatric Medicine and conducted at the SLU Biomedical and Healthcare Research Facility. Logan University and Saint Louis University School of Medicine ethics committee approval was obtained for this study and written consent was obtained from all study participants and CONSORT statement guidelines for collecting data were followed.

Participants were recruited from the outpatient clinic and clinical practices of geriatric physicians in the Department of Internal Medicine, Division of Geriatric Medicine at Saint Louis University School of Medicine. Participants also were recruited through retirement centers, churches, grocery stores, community centers, etc. within the St. Louis metropolitan region (within a 50 mile radius of SLU, in both $\mathrm{MO}$ and IL). Recruitment in retirement centers and churches and other facilities sometimes involved investigators visiting the establishments to give brief presentations about the study and/or to be available to answer questions in-person from individuals who may be interested in participating in the study. There were newspapers advertisements about this study, too. Recruitment flyers were posted in the outpatient clinics of Geriatric Medicine and in retirement centers and churches within the St. Louis metropolitan region. A study brochure was available for prospective patients at recruitment sites (e.g., clinics, retirement centers, churches, etc.). A letter from the study physician was sent to local colleagues/physicians to inform them of this study and to provide them with materials to distribute to their patients and/or to publicize the study at their clinics/offices. To encourage participation in all of the follow up tests, subjects were given a $\$ 20.00$ gift card 
each time they completed a follow-up testing session at 6 and 12 weeks. Every effort was made to coordinate patient schedules with their transportation availability.

\section{Inclusion criteria}

Study participants were community dwelling individuals between the ages of 60-85 with self-reported balance problems. Balance problems are defined as the inability to keep one's center of gravity over the base of support during both static and dynamic situations.

\section{Exclusion criteria}

Study participants were ineligible if they had a history of recent ( $<6$ months) orthopedic fracture or surgery, recent neoplasm (excluding minor skin cancers), acute infectious disease, or non-mechanical low back pain. Patients were also excluded who had unstable peripheral vascular disease and or cardiac disease requiring recent hospitalization ( $<6$ months) ago. Participants also had to be ambulatory with or without an assistive device and could not have Meniere's disease, vertigo, or vestibular disorders or a recent history of substance abuse. Patients currently using antipsychotics, anxiolytics, and sedative/ hypnotics were also excluded. Patients that were receiving ongoing care by a chiropractor or physical therapist were not enrolled into the study.

\section{Patient screening and consenting}

The clinical trial coordinator initially screened interested parties by phone for eligibility criteria. Individuals who passed the initial screening process met with the nurse coordinator who obtained medical and surgical history, falls history and fear of falling, current exercise program, and demographic information (age, sex, ethnicity, years of education, smoking history, and alcohol consumption) (Tables 1 and 2). The use of prescription and over the

Table 1 Patient demographics at time of enrollment

\begin{tabular}{llll}
\hline Characteristics & $\begin{array}{l}\text { Physical therapy } \\
\boldsymbol{n = 8 5 ( 5 0 . 6 \% )}\end{array}$ & $\begin{array}{l}\text { Chiropractic } \\
\text { care } \\
\boldsymbol{n}=\mathbf{8 3} \text { (49.4\%) }\end{array}$ & $\begin{array}{l}\text { Total } \\
\boldsymbol{n}=\mathbf{1 6 8}\end{array}$ \\
\hline Age, mean (SD) & $72.9 \pm 6.9$ & $72.8 \pm 6.8$ & $72.8 \pm 6.8$ \\
\hline Range (median) & $85-60(73.5)$ & $85-60(71.5)$ & $85-60(73)$ \\
\hline Gender & & & \\
\hline Male & $29.4 \%$ & $30.1 \%$ & $29.8 \%$ \\
\hline Female & $70.6 \%$ & $69.9 \%$ & $70.2 \%$ \\
\hline Ethnicity & & $94.9 \%$ & $91.0 \%$ \\
\hline Caucasian & $87.2 \%$ & $5.1 \%$ & $7.7 \%$ \\
\hline African American & $10.3 \%$ & $0 \%$ & $1.3 \%$ \\
\hline Other & $2.5 \%$ & $15.6 \pm 2.3$ & $16.1 \pm 2.2$ \\
\hline Education, mean (SD) & $16.6 \pm 2.1$ & $75.0 \%$ & $63.7 \%$ \\
\hline Exercised & $71.4 \%$ & & \\
\hline
\end{tabular}

SD, standard deviation; education in years.
Table 2 Medical surgical history

\begin{tabular}{llll}
\hline Medical surgical history & $\begin{array}{l}\text { Physical } \\
\text { therapy } \\
\boldsymbol{n}=\mathbf{8 5} \\
\mathbf{( 5 0 . 6 \% )}\end{array}$ & $\begin{array}{l}\text { Chiropractic } \\
\text { care } \\
\boldsymbol{n}=\mathbf{8 3} \\
\mathbf{( 4 9 . 4 \% )}\end{array}$ & $\begin{array}{l}\text { Total } \\
\boldsymbol{n}=\mathbf{1 6 8}\end{array}$ \\
\hline History of Falls & $(46.1 \%)$ & $(48.1 \%)$ & $(47.1 \%)$ \\
\hline Smoker History & $(46.1 \%)$ & $(44.0 \%)$ & $(45.0 \%)$ \\
\hline Smoker Current & $(10.5 \%)$ & $(10.7 \%)$ & $(10.6 \%)$ \\
\hline Hypertension & $(60.2 \%)$ & $(60.5 \%)$ & $(60.4 \%)$ \\
\hline Myocardial Infarction & $(3.6 \%)$ & $(12.3 \%)$ & $(7.9 \%)$ \\
\hline Congestive Heart Failure & $(6.0 \%)$ & $(6.2 \%)$ & $(6.1 \%)$ \\
\hline Non-Insulin Dependent Diabetes & $(18.1 \%)$ & $(8.6 \%)$ & $(13.4 \%)$ \\
\hline Peripheral Vascular Disease & $(3.6 \%)$ & $(4.9 \%)$ & $(4.3 \%)$ \\
\hline Deep Vein Thrombosis & $(2.4 \%)$ & $(8.6 \%)$ & $(5.5 \%)$ \\
\hline Stroke & $(1.2 \%)$ & $(4.9 \%)$ & $(3.0 \%)$ \\
\hline Peripheral Neuropathy & $(10.8 \%)$ & $(13.6 \%)$ & $(12.2 \%)$ \\
\hline Rheumatoid Arthritis & $(2.4 \%)$ & $(2.5 \%)$ & $(2.4 \%)$ \\
\hline Spinal Stenosis & $(8.4 \%)$ & $(8.6 \%)$ & $(8.5 \%)$ \\
\hline Low Back Pain & $(67.1 \%)$ & $(73.5 \%)$ & $(70.2 \%)$ \\
\hline Osteoarthritis & $(59.0 \%)$ & $(50.6 \%)$ & $(54.9 \%)$ \\
\hline Ruptured Disc & $(14.5 \%)$ & $(3.7 \%)$ & $(9.1 \%)$ \\
\hline Dementia & $(0.0 \%)$ & $(1.2 \%)$ & $(0.6 \%)$ \\
\hline Head Injury & $(1.2 \%)$ & $(2.5 \%)$ & $(1.8 \%)$ \\
\hline Other Neurological Injury & $(2.4 \%)$ & $(2.5 \%)$ & $(2.4 \%)$ \\
\hline Head and Neck surgery & $(6.1 \%)$ & $(5.0 \%)$ & $(5.6 \%)$ \\
\hline Coronary artery bypass surgery & $(9.8 \%)$ & $(13.8 \%)$ & $(11.7 \%)$ \\
\hline Lung surgery & $(2.4 \%)$ & $(0.0 \%)$ & $(1.2 \%)$ \\
\hline Gastrointestinal surgery & $(6.1 \%)$ & $(11.3 \%)$ & $(8.6 \%)$ \\
\hline Orthopedic surgery & $(41.5 \%)$ & $(35.0 \%)$ & $(38.3 \%)$ \\
\hline
\end{tabular}

counter medications and supplements were also recorded. The nurse trial coordinator reviewed the study details with participants and obtained written informed consent. Patient medical records were reviewed by the geriatric physician and nurse coordinator prior to patient acceptance into the study. After participants completed functional performance tests and self-report questionnaires, they were randomized into their treatment groups. Participants were re-tested upon completion of treatments at week six and again six weeks later. Testing was performed by an individual blinded to the treatment group assignment.

\section{Outcome measures}

Participants completed both functional performance tests and self-report questionnaires related to balance, pain, and quality of life (Table 3 ). Testing was performed at baseline, after 6 weeks of care, and at 12 weeks. Selfreported questionnaires used were the Falls Efficacy Scale (FES), Tampa Kinesiophobia Scale, Visual analogue scale (VAS), the 21-point Box Pain Scale, the Oswestry Questionnaire, SF-36 Questionnaire. Balance tests included 
Table 3 Subjective and objective measurements

\begin{tabular}{lll}
\hline Test & Variable & Time points \\
\hline $\begin{array}{l}\text { Performance Oriented } \\
\text { Mobility Assessment }\end{array}$ & Balance and gait & Baseline, 6/12 weeks \\
\hline Berg Balance Scale & $\begin{array}{l}\text { Static and dynamic - } \\
\text { balance }\end{array}$ & Baseline, 6/12 weeks \\
\hline $\begin{array}{l}\text { NeuroCom Limits of } \\
\text { Stability Test }\end{array}$ & $\begin{array}{l}\text { Ability to control } \\
\text { sway - balance }\end{array}$ & Baseline, 6/12 weeks \\
\hline NeuroCom Mod CTSIB & Balance & Baseline, 6/12 weeks \\
\hline Timed Get up and Go Test & Gait & Baseline, 6/12 weeks \\
\hline Falls Efficacy Scale & Fear of falling & Baseline, 6/12 weeks \\
\hline Oswestry Disability Index & Low back disability & Baseline, 6/12 weeks \\
\hline SF-36 Questionnaire & $\begin{array}{l}\text { Health related } \\
\text { quality of life }\end{array}$ & Baseline, 6/12 weeks \\
\hline Tampa Kinesiophobia Scale & Fear of movement & Baseline, 6/12 weeks \\
\hline Visual Analog Scale & Pain level - current & Baseline, 6/12 weeks \\
\hline 21 point Box Scale & $\begin{array}{l}\text { Pain - worst, least, } \\
\text { usual, days in pain }\end{array}$ & Baseline, 6/12 weeks \\
\hline
\end{tabular}

the Berg Balance Scale, The Timed Get up and Go (TGUG) test, Performance-oriented mobility assessment (POMA), and NeuroCom Balance assessment tests which included the Limits of Stability (LOS) Test and Modified Clinical test for the sensory integration of Balance (Mod CTSIB). The outcome tests were administered by an investigator blinded to participant treatment condition. All study examiners were trained on the use of the NeuroCom balance master equipment and inter-rater reliability was verified. Participants were also given a $2-3$ minute tutorial on the NeuroCom force plate prior to the beginning of their baseline tests in order to minimize any learning effect that might occur. A flow chart outlining the assessment, testing, randomization, and treatment for study participants is shown in Figure 1.

\section{Self-reported questionnaires}

- The Falls Efficacy Scale (FES) is a validated instrument with good test-retest reliability (Pearson's correlation 0.71) that measures fear of falling and is a measure of functional decline among the elderly. The highest FES scores characterizing lower self-efficacy or confidence are seen in people avoiding essential activities of daily living because of fear of falling $[27,28]$.

- Visual analogue scale (VAS) - The VAS is a 0 to 10 scale that reliably measures subjective pain experience and is used extensively in musculoskeletal pain studies $[29,30]$. Increased VAS pain scores correlate with increased self-rated disability [31].

- The 21-point box scale assesses current, past and usual pain with a series of horizontal boxes labeled from 0-100 in 5-point increments with verbal anchors at 0 ("No Pain") and 100 ("Pain as bad as it could be").

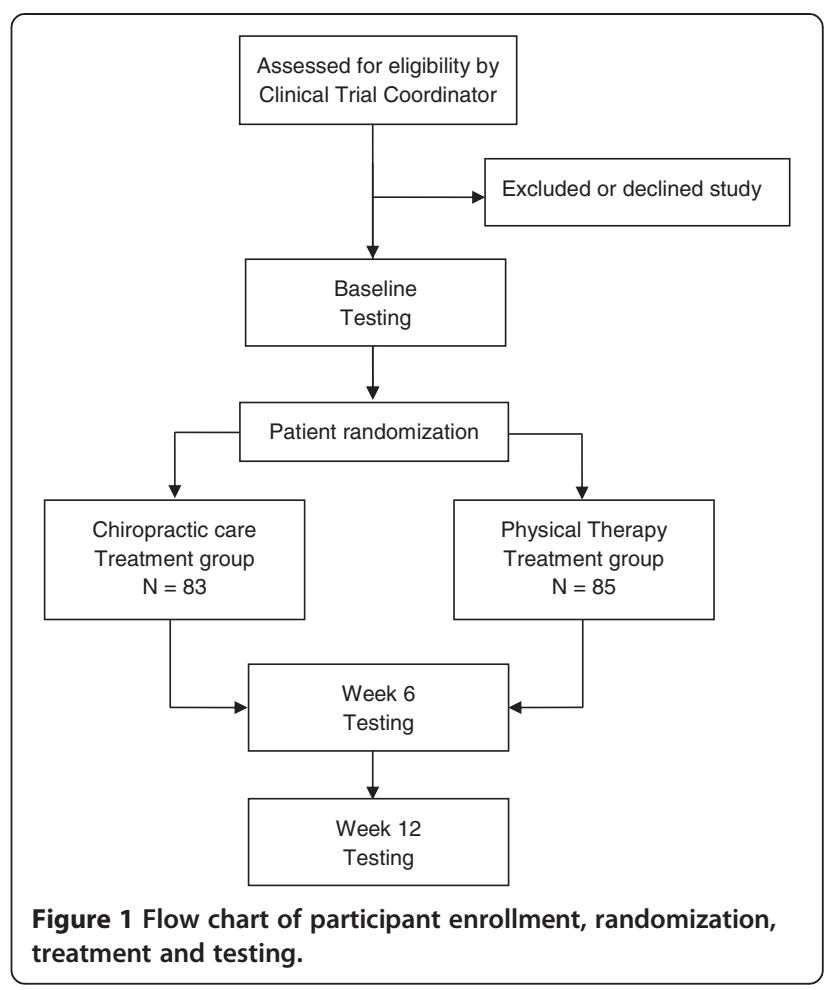

This scale has been validated and is recommended for pain assessment in older adults [31,32].

- The Oswestry Questionnaire evaluates changes in patient function and evaluates capability to perform day-to-day activities or the level of impairment occurring as a result of a spinal condition and has a reliability coefficient ranging from 0.83 to 0.99 . A score of 0 on the questionnaire indicates the complete absence of a disability, whereas 100 indicates an incapacitating condition [33].

- The SF-36 Questionnaire is a generic health questionnaire that is used in conjunction with disease-specific questionnaires to obtain a wide perspective of the burden of patient ill health. The responsiveness of the SF-36 questionnaire can be a useful adjunct in the assessment of patients with low back pain when combined with disease-specific questionnaires [34].

- Tampa Scale for Kinesiophobia is a measure of how a patient's fear of movement relates to their fear of re-injury. The patient rates 17 statements that indicate whether movement related pain is a warning for re-injury. Several studies have found the scale to be a valid and reliable psychometric measure [35-37].

\section{Balance tests}

- The Berg Balance Scale (BBS) is a functional test that assesses a patient's ability to maintain balance, 
either statically or while performing various functional movements, and is considered to be the gold standard among functional balance tests. The maximum score of 56 denotes good balance and a score of 45 is required for safe independent living. The test has an interrater reliability intraclass correlation coefficients of 0.98 ; intrarater reliability intraclass correlation coefficient 0.99 [38-40].

- The Timed Get up and Go (TGUG) is a sensitive and specific timed functional gait and balance test for identifying community dwelling and frail adults who are at risk for falls. It involves the patient getting up from a chair without using their arms, walking 3 meters, turning and walking back to the chair and sitting down. Mobility impairments are directly related to the time needed to complete the test [41-43]. The mean (95\% confidence interval) TUG time for individuals at least 60 years of age is 9.4 (8.9 - 9.9) seconds [44]. Individuals whose TUG time exceeds this may warrant interventions directed at improving their strength, balance, and/or mobility.

- Performance-oriented mobility assessment (POMA), also known as the Tinetti balance and gait scale, is one of the most widely used assessments of balance, gait, and falls risk in older adults. The POMA includes an evaluation of balance under static and dynamic conditions and an evaluation of gait characteristics. A score of less than 19 out of 28 has a sensitivity of $68 \%$ and a specificity of $88 \%$ for predicting an individual who will have two or more falls [45-47].

The NeuroCom Balance Master is a computerized testing system used to identify ankle and knee contributions to weight shifting during balance and evaluate the ability to integrate the somatosensory, vestibular and visual systems that interact during normal balance.

- The NeuroCom Limits of Stability Test (LOS) assesses a patient's ability to control voluntarily sway to various points and maintain stability at each position for brief periods of time. For each of eight trials, the patient maintains their center of gravity (COG) over the base of support as indicated by a cursor display of the COG position relative to a center target. On command, the patient moves the COG cursor as quickly and accurately as possible towards a second target located on the LOS perimeter (100\% of theoretical limits of stability) and then holds a position as close to the target as possible. The patient is allowed up to 8 seconds to complete each trial. The limits of stability measures the maximum distance a person can lean in various directions without losing balance as well as measuring the reaction time, speed, direction, and distance of the COG (Figures 2 and 3).

The scores shown in Figure 2 indicate that this subject had a slower reaction time and movement velocity when leaning forward and to their left. However, compared to others in their age range, the distance they could move their COG to the target (max excursion) was above average in each direction as was their directional control. Compare this with the scores of a second subject (Figure 3). Of specific note are the overall decreases in max excursion and directional control in each of the eight trials, specifically when attempting to move in the backward direction. Decreased values of any of the parameters can predict an increased fall risk, instability during weight-shifting activities, and inability to perform weight-shifting activities $[48,49]$. The NeuroCom LOS test has shown a test-retest reliability ranging from high to low across the LOS measures (ICC2,k 0.82 to 0.48) and concurrent and construct validity of the LOS tests are not definitively established [50].

- The NeuroCom Modified Clinical Test for the Sensory Integration of Balance (Mod CTSIB) measures postural sway velocity under four different conditions: eyes open on a firm surface, eyes closed on a firm surface, eyes open on a foam surface, and eyes closed on a foam surface. This test is able to identify abnormalities in somatosensory, visual, and vestibular systems related to postural control. The mCTSIB has shown to have excellent test-retest reliability $(\mathrm{ICC}=0.91)$ and excellent interrater reliability $(r=0.99)$ [51,52]. Increased sway velocity leads to postural instability, especially when performing tasks on an unstable surface or in low light or darkness. Due to the learning effect that happens when performing the test, a criterion of an 8 point improvement in the composite score is needed to indicate improvement in balance function [53].

\section{Treatments}

Both physical therapy and chiropractic treatments were provided at the Saint Louis University School of Medicines' Center for Biomedical and Healthcare research. Evidence based practice guidelines were followed by the chiropractors and Physical Therapist in determining treatment options for each individual patient in the study. Chiropractic care was delivered by a licensed chiropractic physician and based on standard examination findings, including orthopedic testing, range of motion assessment, and evaluation of pain or tenderness. Palpation also documented changes in tissue, asymmetry or misalignment. Chiropractic care focused on the thoracic and lumbar 


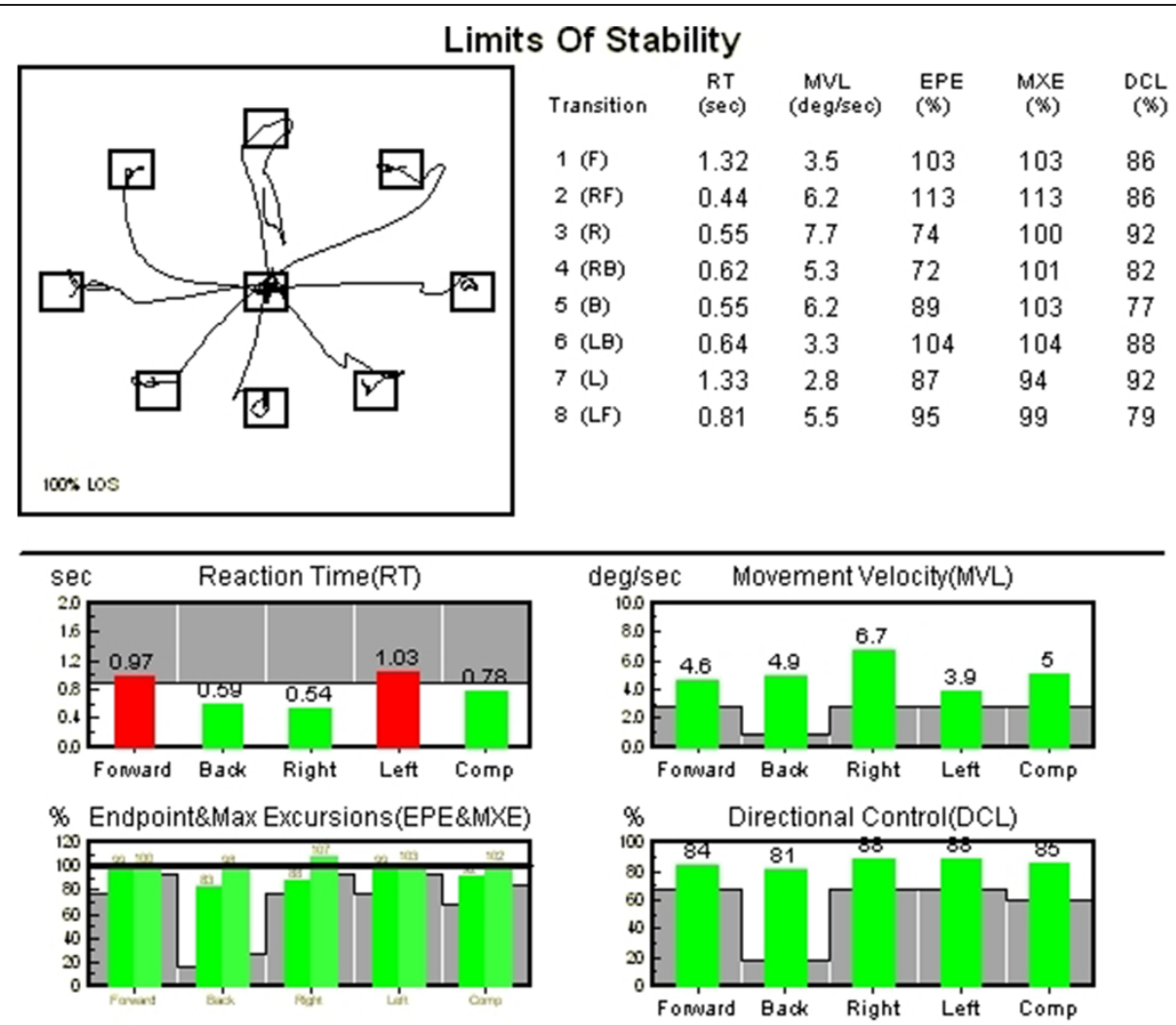

Figure 2 The NeuroCom limits of stability test (LOS) measuring reaction time, movement velocity, end point excursion, and directional control during controlled voluntary shifting of the center of gravity. This graph shows slower reaction time and movement velocity, especially leaning forward and left. The maximum excursion and directional control was above average compared to their age cohort.

spine and the lower extremity and included any combination of the following treatment options: manipulation, mobilization, flexion-distraction therapy and stretching and gentle soft tissue therapy with the goal of increased joint mobility, restoration of normal function, and increased flexibility. Physical therapy was delivered by a licensed Physical Therapist and based on patient history, initial patient evaluation, and examination findings. Physical therapy techniques may include any combination of the following treatment options: TENS units, interferential electrical stimulation, ultrasound, flexibility stretches, muscle endurance and strength training exercises, neuromuscular reeducation as well as instruction on proper posture and lifting techniques, safety training, and education on a home exercise program.

\section{Study population}

All participants enrolled in this study reported had selfreported balance problems, and 72 participants $(47 \%)$ had a history of falls. One hundred and eighteen participants (70.2\%) reported current low back pain (LBP) at baseline testing, and 50 participants $(29.8 \%)$ reported no back pain. The presence of back pain had no effect on randomization and was identified at baseline testing with the VAS and 21 point box pain scale. Eighty five participants (50.6\%) were randomized into the physical therapy group and eighty three (49.4\%) were randomized into the chiropractic care group. The physical therapy group consisted of fifty seven participants (67.1\%) with LBP and twenty eight participants (32.9\%) without LBP. The chiropractic group consisted of sixty one participants (73.5\%) with LBP and twenty two participants (26.5\%) without LBP. The number of participants enrolled met power calculations for adequate sample size.

\section{Data analysis and sample size}

This randomized, controlled mixed-model design included a repeated measures variable for time (baseline, week 6 , \& week 12) and a between subjects variable for treatment (chiropractic vs. physical therapy). This intention-to-treat design data analysis included a mixed-model analysis of variance $(A N O V A)(p<0.05)$ for each outcome measure, with a Bonferroni correction of $\mathrm{p}<0.017$ for the main balance measures and $\mathrm{p}<0.025$ for main pain measures (SPSS Statistics version 20.0, IBM Corp., Somers, NY). The power to detect a main effect of study group (chiropractic vs. physical therapy) is a function of sample size $(n=75$ per group) and the alpha level of 0.05 for 
statistical significance. At a power level of $1-\beta=0.80$, this study was sufficiently powered to detect a main effect of treatment group at effect sizes of $\mathrm{f}>0.19$ to evaluate the primary study outcome measures. The values of the $f$ effect size are interpreted as follows: $0.10-0.24$ is considered small effects, $0.25-0.39$ is considered medium effects, and values $>0.40$ are considered large effects $[54,55]$. Data will be screened prior to the main data analysis following standard procedures [56].

\section{Discussion}

While they represent the fastest growing segment of the population, only 4.6 percent of adults over the age of seventy utilize chiropractic care [57]. Studies involving chiropractic care as a treatment option for balance problems in this age cohort also remain under represented $[1,25]$. There remain important research questions we hope to address in this study. Consistent with the goals of evidence based care, increasing the number of effective patient treatment options is a primary aspect of this study. A direct comparison between chiropractic care and physical therapy outcomes adds to the evidence based guidelines for the geriatric patient. To further define the effectiveness of specific treatments on patient reaction time, postural control, and gait characteristics, multiple functional performance tests and self-report questionnaires were performed.

The strength of this study included well-defined treatment protocols, with equal numbers of participants and gender representation randomized into those groups. The gender allocation in this study was comparable to that of the general geriatric population. Even though LBP was not considered in the randomization process, there were an equal number of participants with LBP in the chiropractic care and physical therapy groups. There was also a comparable distribution of participant comorbidities between the two treatment groups. To ensure consistency of care, all treatments were provided by the same chiropractor and physical therapist, both having previous experience focusing on geriatric care. Considering the advanced age of some participants, completion of all testing sessions was issue. Some potential subjects had difficulty acquiring transportation to and from clinic sites. Older adults who resided in long term care 
facilities, were home bound, or did not speak English were not represented in this study.

Many novel therapies and rehabilitation techniques involving older adults with postural control problems are of unknown effectiveness and warrant further investigation [55]. This randomized controlled clinical trial compared chiropractic and physical therapy for older adults with balance problems and with or without low back pain.

\section{Conclusion}

The methodology and patient demographics from a 4year prospective, randomized controlled double blinded clinical trial is presented. This study evaluated chiropractic or physical therapy as a treatment for geriatric patients with balance disorders and with or without low back pain.

\section{Consent}

Written informed consent was obtained from all study participants. University ethics committee approval was obtained for this study.

\section{Competing interests}

The authors declare that they have no competing interests.

\section{Authors' contributions}

All authors contributed to this clinical trial and the manuscript. DE is the study principal investigator and program director. DE, JF \& TM contributed to the study design. DE and KS reviewed the literature and created the first manuscript draft, TM was responsible for analysis and interpretation of data. All authors provided critical review and approved the final manuscript.

\section{Acknowledgements}

The authors would like to thank graduate student Robbyn Keating for manuscript review.

\section{Grants}

This research was funded by grant award number 1 R18HP15125-01-00 from the U.S. Department of Health and Human Services (HHS); Health Resources and Services Administration (HRSA).

\section{Author details}

${ }^{1}$ Research Division, Logan University, 1851 Schoettler Rd, Chesterfield, MO 60317, USA. ${ }^{2}$ Department of Neurology \& Psychiatry, Saint Louis University School of Medicine, St. Louis, MO 63104, USA. ${ }^{3}$ Department of Internal Medicine \& Division of Geriatrics, Saint Louis University School of Medicine, St. Louis, MO 63104, USA.

Received: 10 January 2014 Accepted: 26 August 2014

Published online: 13 September 2014

\section{References}

1. Bressler HB, Keyes WJ, Rochon PA, Badley E: The prevalence of low back pain in the elderly: a systematic review of the literature. Spine 1999, 24(17):1813-1819.

2. Weiner DK, Sakamoto S, Perera S, Breuer P: Chronic low back pain in older adults: prevalence, reliability, and validity of physical examination findings. J Am Geriatr Soc 2006, 54(1):11-20.

3. Strine TW, Hootman JM: US national prevalence and correlates of low back and neck pain among adults. Arthritis Rheum 2007, 57(4):656-665.

4. Deyo RA, Mirza SK, Martin Bl: Back pain prevalence and visit rates: estimates from U.S. national surveys, 2002. Spine 2006, 31:2724-2727.
5. Jacobs J, Andersson GBJ, Bouchard JE, Bozic KJ, Campbell RM, Cisternas MG, Correa A, Cosman F, Cragan JD, D'Andrea K, Doernberg N, Dormans JP, Elderkin AL, Fershteyn Z, Foreman AJ, Gitelis S, Gnatz SM, Haralson RH, Helmick CG, Hochberg MC, Hu S, Katz JN, King T, Kirk R: United States Bone \& Joint Decade: the burden of musculoskeletal diseases in the United States. 2nd edition. Rosemont, IL: American Academy of Orthopaedic Surgeons; 2011. ISBN 978-0-89203-749-0 ISBN 978-0-89203-533-5.

6. Blake AJ, Morgan K, Bendall MJ, Dallosso H, Ebrahim SBJ, Arie THD, Fentem $\mathrm{PH}$, Bassey EJ: Falls by elderly people at home: prevalence and associated factors. Age Ageing 1988, 17(6):365-372.

7. Hicks GE, Gaines JM, Shardell M, Simonsick EM: Associations of back and leg pain with health status and functional capacity of older adults: findings from the retirement community back pain study. Arthritis Rheum 2008, 59(9):1306-1313.

8. Leveille SG, Jones RN, Kiely DK, Hausdorff JM, Shmerling RH, Guralnik JM, Kiel DP, Lipsitz DA, Bean JF: Chronic musculoskeletal pain and the occurrence of falls in an older population. JAMA 2009, 302(20):2214-2221.

9. Michael YL, Whitlock EP, Lin JS, Fu R, O'Connor EA, Gold R: Primary carerelevant interventions to prevent falling in older adults: a systematic evidence review for the U.S. Preventive Services Task Force. Ann Intern Med 2010, 153(12):815-825.

10. Sterling M, Jull G, Wright A: The effect of musculoskeletal pain on motor activity and control. J Pain 2001, 2(3):135-145.

11. Brumagne S, Cordo P, Lysens R, Verschueren S, Swinnen S: The role of paraspinal muscle spindles in lumbosacral position sense in individuals with and without low back pain. Spine 2000, 25(8):989-994.

12. Hides JA, Stokes MJ, Saide M, Jull GA, Cooper DH: Evidence of lumbar multifidus muscle wasting ipsilateral to symptoms in patients with acute/subacute low back pain. Spine 1994, 19(2):165-172.

13. Hungerford B, Gilleard W, Hodges P: Evidence of altered lumbopelvic muscle recruitment in the presence of sacroiliac joint pain. Spine 2003, 28(14):1593-1600.

14. Melzer I, Benjuya N, Kaplanski J: Postural stability in the elderly: a comparison between fallers and non-fallers. Age Ageing 2004, 33(6):602-607.

15. Sipko T, Kuczynski M: The effect of chronic pain intensity on the stability limits in patients with low back pain. J Manipulative Physiol Ther 2013, 36(9):612-618.

16. Jones SL, Henry SM, Raasch CC, Hitt JR, Bunn JY: Individuals with nonspecific low back pain use a trunk stiffening strategy to maintain upright posture. J Electromyography Kinesiol 2012, 22(1):13-20.

17. Jacobson GP, Newman CW, Kartush JM: Handbook of balance function testing. In Thompson Delmar Learning. 1st edition. NY: Cengage Learn; 1997:9. ISBN 1-5659-3907-7.

18. Barnett A, Smith B, Lord SR, Williams M, Baumand A: Community-based group exercise improves balance and reduces falls in at-risk older people: a randomized controlled trial. Age Ageing 2003, 32(4):407-414.

19. Chang J, Morton S, Rubenstein L, Mojica W, Maglione M, Suttorp M: Interventions for the prevention of falls in older adults: a systematic review and meta-analysis of randomized clinical trials. Br Med J 2004, 328:680-688.

20. Sherrington C, Whitney JC, Lord SR, Herbert RD, Cumming RG, Close JC: Effective exercise for the prevention of falls: a systematic review and meta-analysis. J Am Geriatr Soc 2008, 56(12):2234-2243.

21. Keller TS, Colloca CJ, Gunzburg R: Neuromechanical characterization of in vivo lumbar spinal manipulation. Part I: vertebral motion. J Manipulative Physiol Ther 2003, 26(9):567-578.

22. Keller TS, Colloca CJ, Moore RJ, Gunzburg R, Harrison DE: Increased multiaxial lumbar motion responses during multiple-impulse mechanical force manually assisted spinal manipulation. Chiropr Osteopat 2006, 14:6.

23. Mieritz RM, Hartvigsen J, Boyle E, Jakobsen MD, Aagaard P, Bronfort G: Lumbar motion changes in chronic low back pain patients: a secondary analysis of data from a randomized clinical trial. Spine J 2014, 7:S1529-9430(14)00239-3.

24. Imagama S, Ito Z, Wakao N, Seki T, Hirano K, Muramoto A, Sakai Y, Matsuyama Y, Hamajima N, Ishiguro N, Hasegawa Y: Influence of spinal sagittal alignment, body balance, muscle strength, and physical ability on falling of middle-aged and elderly males. Eur Spine J 2013, 22(6):1346-1353.

25. Hawk C, Cambron JA, Pfefer MT: Pilot study of the effect of a limited and extended course of chiropractic care on balance, chronic pain, and dizziness in older adults. J Manipulative Physiol Ther 2009, 32(6):438-447. 
26. Hawk C, Strunk R, Ramcharan M, Uhl N: Feasibility study of short effects of chiropractic manipulation on older adults with impaired balance. J Chiropr Med 2007, 6(4):121-131.

27. Tinetti ME, Richman D, Powell L: Falls efficacy as a measure of fear of falling. J Gerontol 1990, 45(6):239-243.

28. Tinetti ME, Mendes de Leon CF, Doucette JT, Baker DI: Fear of falling and fall-related efficacy in relationship to functioning among communityliving elders. J Gerontol 1994, 49(3):M140-M147.

29. Price DD, McGrath PA, Rafii A, Buckingham B: The validation of visual analogue scales as ratio scale measures for chronic and experimental pain. Pain 1983, 17(1):45-56.

30. Boulgarides LK, McGinty SM, Willett JA, Barnes CW: Use of clinical and impairment-based tests to predict falls by community-dwelling older adults. Phys Ther 2003, 83(4):328-339.

31. Chibnall JT, Tait RC: Pain assessment in cognitively impaired and unimpaired older adults: a comparison of four scales. Pain 2001, 92(1-2):173-186

32. Taylor SJ, Taylor AE, Foy MA, Fogg AJ: Responsiveness of common outcome measures for patients with low back pain. Spine 1999, 24(17):1805-1812.

33. Fairbank JC, Pynsent PB: The Oswestry disability index. Spine 2000, 25(22):2940-2952. discussion 2952.

34. Jenkinson C, Wright $L$, Coulter A: Criterion validity and reliability of the SF-36 in a population sample. Qual Life Res 1994, 3(1):7-12.

35. Lame IE, Peters ML, Kessels AG, Van Kleef M, Patijn J: Test-retest stability of the pain Catastrophizing scale and the Tampa scale for Kinesiophobia in chronic pain over a longer period of time. J Health Psychol 2008 13(6):820-826

36. Damsgard E, Fors T, Anke A, Roe C: The Tampa scale of Kinesiophobia: a Rasch analysis of its properties in subjects with low back and more widespread pain. J Rehabil Med 2007, 39(9):672-678.

37. Bunketorp L, Carlsson J, Kowalski J, Stener-Victorin E: Evaluating the reliability of multi-item scales: a non-parametric approach to the ordered categorical structure of data collected with the Swedish version of the Tampa Scale for Kinesiophobia and the self-efficacy scale. J Rehabil Med 2005, 37(5):330-334

38. Berg KO, Wood-Dauphinee SL, Williams JI, Maki B: Measuring balance in the elderly: validation of an instrument. Can J Public Health 1992, 83(Suppl 2):S7-S11.

39. Bogle Thorbahn LD, Newton RA: Use of the Berg balance test to predict falls in elderly persons. Phys Ther 1996, 76(6):576-583. discussion 584-575.

40. Berg K: Measuring balance in the elderly: preliminary development of an instrument. Physio Can 1989, 41(6):304-311.

41. Mathias S, Nayak US, Isaacs B: Balance in elderly patients: the "get-up and go" test. Arch Phys Med Rehabil 1986, 67(6):387-389.

42. Podsiadlo D, Richardson S: The timed "Up \& Go": a test of basic functional mobility for frail elderly persons. J Am Geriatr Soc 1991, 39(2):142-148.

43. Shumway-Cook A, Brauer S, Woollacott M: Predicting the probability for falls in community-dwelling older adults using the timed up \& go test. Phys Ther 2000, 80(9):896-903.

44. Bohannon RW: Reference values for the timed up and go test: a descriptive meta-analysis. J Geriatr Phys Ther 2006, 29(2):64-68.

45. Tinetti ME: Performance-oriented assessment of mobility problems in elderly patients. J Am Geriatr Soc 1986, 34(2):119-126.

46. Guralnik JM, Ferrucci L, Simonsick EM, Salive ME, Wallace RB: Lowerextremity function in persons over the age of 70 years as a predictor of subsequent disability. N Engl J Med 1995, 332(9):556-561.

47. Guralnik JM, Simonsick EM, Ferrucci L, Glynn RJ, Berkman LF, Blazer DG, Scherr PA, Wallace RB: A short physical performance battery assessing lower extremity function: association with self-reported disability and prediction of mortality and nursing home admission. J Gerontol 1994, 49(2):M85-M94.

48. Clark S, Rose DJ, Fujimoto K: Generalizability of the limits of stability test in the evaluation of dynamic balance among older adults. Arch Phys Med Rehabil 1997, 78(10):1078-1084.

49. Clark S, Rose DJ: Evaluation of dynamic balance among communitydwelling older adult fallers: a generalizability study of the limits of stability test. Arch Phys Med Rehabil 2001, 82(4):468-474.

50. Pickerill ML, Harter RA: Validity and reliability of limits-of-stability testing: a comparison of 2 postural stability evaluation devices. J Athlet Train 2011, 46(6):600-606.
51. Suttanon P, Hill KD, Dodd KJ, Said CM: Retest reliability of balance and mobility measurements in people with mild to moderate Alzheimer's disease. Int Psychogeriatr 2011, 23(7):1152-1159.

52. Cohen H, Blatchly CA, Gombash LL: A study of the clinical test of sensory interaction and balance. Phys Ther 1993, 73(6):346-351. discussion 351-344.

53. Wrisley DM, Stephens MJ, Mosley S, Wojnowski A, Duffy J, Burkard R: Learning effects of repetitive administrations of the sensory organization test in healthy young adults. Arch Phys Med Rehabil 2007, 88(8):1049-1054.

54. Cohen J: Statistical power analysis for the behavioral sciences. Hillsdale $\mathrm{NJ}$ Erlbaum 1988, 8:273-288.

55. Faul F, Erdfelder E, Lang AG, Buchner A: G*Power 3: a flexible statistical power analysis program for the social, behavioral, and biomedical sciences. Behav Res Methods 2007, 39(2):175-191.

56. Tabachnick BG, Fidell LS: Using multivariate statistics. 5th edition. Boston: Allyn and Bacon; 2007. ISBN: 0205459382; 9780205459384; 0205465250; 9780205465255 .

57. Wolinsky FD, Liu L, Miller TR, Geweke JF, Cook EA, Greene BR, Wright KB, Chrischilles EA, Pavlik CE, An H, Ohsfeldt RL, Richardson KK, Rosenthal GE, Wallace RB: The use of chiropractors by older adults in the United States. Chiropr Osteopat 2007, 15:12.

\section{doi:10.1186/s12998-014-0031-x}

Cite this article as: Enix et al:: Methodology and demographics of a single blinded, randomized controlled trial of chiropractic compared to physical therapy for balance impairments in community dwelling geriatric patients with or without low back pain. Chiropractic \& Manual Therapies 2014 22:31.

\section{Submit your next manuscript to BioMed Central and take full advantage of:}

- Convenient online submission

- Thorough peer review

- No space constraints or color figure charges

- Immediate publication on acceptance

- Inclusion in PubMed, CAS, Scopus and Google Scholar

- Research which is freely available for redistribution 